\title{
Control of Extracellular Dopamine at Dendrite and Axon Terminals
}

\author{
Christopher P. Ford, ${ }^{1}$ Stephanie C. Gantz, ${ }^{1}$ Paul E. M. Phillips, ${ }^{2}$ and John T. Williams ${ }^{1}$ \\ ${ }^{1}$ Vollum Institute, Oregon Health \& Science University L474, Portland, Oregon 97239, and ${ }^{2}$ Department of Psychiatry and Behavioral Sciences and \\ Department of Pharmacology, University of Washington, Seattle, Washington 98195
}

\begin{abstract}
Midbrain dopamine neurons release dopamine from both axons and dendrites. The mechanism underlying release at these different sites has been proposed to differ. This study used electrochemical and electrophysiological methods to compare the time course and calcium dependence of somatodendritic dopamine release in the ventral tegmental area (VTA) and substantia nigra pars compacta (SNc) to that of axonal dopamine release in the dorsal striatum. The amount of dopamine released in the striatum was $\sim 20$-fold greater than in cell body regions of the VTA or SNc. However, the calcium dependence and time to peak of the dopamine transients were similar. These results illustrate an unexpected overall similarity in the mechanisms of dopamine release in the striatum and cell body regions. To examine how diffusion regulates the time course of dopamine following release, dextran was added to the extracellular solution to slow diffusion. In the VTA, dextran slowed the rate of rise and fall of the extracellular dopamine transient as measured by fast-scan cyclic voltammetry yet did not alter the kinetics of the dopamine-dependent IPSC. Dextran failed to significantly alter the time course of the rise and fall of the dopamine transient in the striatum, suggesting a more influential role for reuptake in the striatum. The conclusion is that the time course of dopamine within the extracellular space of the VTA is dependent on both diffusion and reuptake, whereas the activation of $\mathrm{D}_{2}$ receptors on dopamine neurons is primarily limited by reuptake.
\end{abstract}

\section{Introduction}

The release of dopamine in forebrain terminal regions such as the striatum, nucleus accumbens, and prefrontal cortex serves as an important behavioral signal that underlies goal-oriented actions and movements (Schultz, 2007). Dopamine neurons of the ventral tegmental area (VTA) and substantia nigra pars compacta $(\mathrm{SNc})$ also release dopamine from somatodendritic sites in the midbrain (Björklund and Lindvall, 1975; Geffen et al., 1976; Cheramy et al., 1981; Jaffe et al., 1998). The dendritic release of dopamine results in a feedback inhibition of dopamine neurons that regulates their excitability (Lacey et al., 1987; Beckstead et al., 2004), thereby decreasing dopamine release in terminal areas.

The release of dopamine from axons and dendrites occurs via vesicular exocytosis; however, the mechanisms that regulate exocytosis may differ between the two sites (Rice et al., 1997; Jaffe et al., 1998; Li et al., 2005; Fortin et al., 2006; John et al., 2006). Axonal release depends upon extracellular calcium entry through voltage-gated calcium channels (VGCCs) (Herdon and Nahorski, 1989; Moghaddam and Bunney, 1989; Phillips and Stamford, 2000; Chen and Rice, 2001; Chen et al., 2006). Somatodendritic release is also calcium dependent, yet conflicting results exist regarding the extent to which release depends upon extracellular calcium influx. In some instances, release has been reported to

Received Feb. 25, 2010; revised March 25, 2010; accepted April 5, 2010.

This work was supported by National Institutes of Health Grants DA026417 (C.P.F.), DA04523 (J.T.W.), and DA17155 and DA24140 (P.E.M.P.).

Correspondence should be addressed to Christopher P. Ford, Vollum Institute, Oregon Health \& Science University L474, 3181 SW Sam Jackson Park Road, Portland, OR 97239. E-mail: fordc@ohsu.edu.

DOI:10.1523/JNEUROSCI.1020-10.2010

Copyright $\odot 2010$ the authors $\quad 0270-6474 / 10 / 306975-09 \$ 15.00 / 0$ exhibit a weak dependence on calcium entry. Thus release persists in low external calcium and is more resistant to inhibition of VGCCs (Hoffman and Gerhardt, 1999; Chen and Rice, 2001, 2002; Chen et al., 2006). Other reports indicate that somatodendritic release shows a steep dependence on external calcium entry such that release is completely inhibited with blockers of VGCCs (Jaffe et al., 1998; Beckstead et al., 2004; Ford et al., 2007; Kim et al., 2008). It remains unclear whether similar mechanisms regulate the release of dopamine in the cell body region and axon terminal fields.

The time course of the rise and fall of extracellular dopamine following synaptic release also has been reported to differ between the midbrain and striatum. In the striatum, the concentration of dopamine peaks within $\sim 200 \mathrm{~ms}$ and is cleared after several hundred milliseconds (Benoit-Marand et al., 2001; Chen and Rice, 2001; Phillips et al., 2002). In the midbrain, however, the reduced rate of dopamine uptake by the dopamine transporter (DAT) and an increased extracellular volume fraction results in a prolonged rise in extracellular dopamine (Rice and Nicholson, 1991; Garris and Wightman, 1994; Cragg and Greenfield, 1997; Cragg et al., 2001; Cragg and Rice, 2004; Rice and Cragg, 2008). Thus it has been reported that in the SNc extracellular dopamine peaks 2000-3000 ms after a single stimulus and remains elevated for several seconds (Chen and Rice, 2001; Chen et al., 2006).

As opposed to the long-lasting extracellular presence of dopamine that has been proposed based on electrochemical techniques, the physiological actions of dopamine in the midbrain have recently been found to be relatively brief (Ford et al., 2009). Dendritic release of dopamine activates $\mathrm{D}_{2}$ receptors on adjacent 
dopamine neurons, leading to the activation of an inwardly rectifying potassium conductance (GIRK/Kir 3.2) (Beckstead et al., 2004). The subsequent IPSC ( $D_{2}$-IPSC) is mediated by a dopamine transient that is $<100 \mathrm{~ms}$. Thus dopamine transmission in the midbrain is more rapid than previously thought (Ford et al., 2009). To examine the mechanisms regulating the extracellular presence of dopamine, the present study has now examined release in the VTA and SNc and the striatum. The results indicate that the time course of the release of dopamine is remarkably similar in all areas.

\section{Materials and Methods}

Slice preparation and visualization. Ice-cold physiological saline solution containing (in mM) $126 \mathrm{NaCl}, 2.5 \mathrm{KCl}, 1.2 \mathrm{MgCl}_{2}, 2.4 \mathrm{CaCl}_{2}, 1.4$ $\mathrm{NaH}_{2} \mathrm{PO}_{4}, 25 \mathrm{NaHCO}_{3}, 11$ D-glucose, and $0.005 \mathrm{MK}-801$ was used to cut midbrain horizontal slices containing the VTA and SNc $(220 \mu \mathrm{m})$ or coronal slices containing the dorsal striatum $(250 \mu \mathrm{M})$ from male and female 5- to 8-week-old DBA/2J mice (The Jackson Laboratory). Slices were incubated in warm $\left(35^{\circ} \mathrm{C}\right) 95 \% \mathrm{O}_{2} / 5 \% \mathrm{CO}_{2}$ oxygenated saline containing $10 \mu \mathrm{M} \mathrm{MK}-801$ for at least $30 \mathrm{~min}$ before recording. Slices were visualized with an Olympus BX51WI (Olympus America) microscope equipped with custom-built gradient contrast infrared optics.

The VTA was defined as an area that began medial to the medial lemniscus, while the $\mathrm{SNc}$ was defined as an area that began lateral to the medial terminal nucleus of the accessory optic tract (MT) (Ford et al., 2006, 2007). For experiments involving dextran, due to the slow penetration of dextran into tissue, slices were preincubated for $>1 \mathrm{~h}$ in dextran solution (10\%) before recording. To account for the slowing of the viscous dextran solution through the bath lines, the height of the dextran solution bottle was raised to ensure even flow $(\sim 1.5 \mathrm{ml} / \mathrm{min})$ of solution through the bath.

Electrophysiology. Whole-cell recordings were made with 1.5-2.5 M $\Omega$ pipettes, using an Axopatch 200B amplifier (Molecular Devices). The pipette internal solution contained (in $\mathrm{mM}$ ) $115 \mathrm{~K}$-methylsulfate, 20 $\mathrm{NaCl}, 1.5 \mathrm{MgCl}_{2}$, 5 HEPES, 10 BAPTA, 2 ATP, and 0.3 GTP; pH 7.3, 270 mOsm. Cells were voltage clamped at $-60 \mathrm{mV}$. Oxygenated saline $\left(35^{\circ} \mathrm{C}\right)$ similar to cutting was used for recordings. Dopamine neurons were identified by the presence of a $D_{2}$-sensitive dopamine IPSC and pacemaker $(1-5 \mathrm{~Hz})$ firing with spikes exhibiting AP widths of $\geq 1.2 \mathrm{~ms}$ (measured in cell-attached voltage-clamp mode from the initial inward current to the peak of the outward current) (Ford et al., 2006). For the pharmacological isolation of the $\mathrm{D}_{2}$-IPSC, the external solution contained picrotoxin $(100 \mu \mathrm{M})$, DNQX $(10 \mu \mathrm{M})$, CGP $55845(200 \mathrm{nM})$, and MK-801 $(10 \mu \mathrm{M})$. To elicit dopamine release, a monopolar saline-filled glass electrode $(\sim 5 \mathrm{M} \Omega)$ was used. Either single stimulus $(0.6 \mathrm{~ms})$ or trains of stimuli ( 5 stimuli at $40 \mathrm{~Hz}$ ) were used. Stimuli were set to $75 \%$ of maximum. Electrophysiological data were acquired using Axograph X (Axograph Scientific).

Electrochemistry. Carbon fibers (34-700, Goodfellow; $7 \mu \mathrm{m}$ diameter) were pulled in glass electrodes and cut to a final exposed length of $\sim 30$ $\mu \mathrm{m}$. The cut electrode tip was placed in isopropanol purified with activated carbon for $10 \mathrm{~min}$ before using. Voltammetric recordings were performed with triangular waveforms at $10 \mathrm{~Hz}$ while holding the electrode at $-0.4 \mathrm{~V}$ between scans. Two separate waveforms were used: one from -0.4 to $1.0 \mathrm{~V}$ versus $\mathrm{Ag} / \mathrm{AgCl}$ at $300 \mathrm{~V} / \mathrm{s}$ (see Fig. 1), and one from $-0.4 \mathrm{~V}$ to $1.3 \mathrm{~V}$ versus $\mathrm{Ag} / \mathrm{AgCl}$ at $400 \mathrm{~V} / \mathrm{s}$ (see Figs. 2-7). The cyclic voltammetric response exhibits greater sensitivity, yet reduced temporal kinetics when a higher potential limit $(1.3 \mathrm{~V})$ and faster scan rates $(400$ $\mathrm{V} / \mathrm{s}$ ) are used (Heien et al., 2003). Thus, waveforms with lower potential limits and scan rates $(1.0 \mathrm{~V}, 300 \mathrm{~V} / \mathrm{s})$ were used to examine the kinetics of changes in extracellular dopamine, while waveforms with higher potential limits and faster scan rates $(1.3 \mathrm{~V}, 400 \mathrm{~V} / \mathrm{s})$ were used in the remainder of the experiments. Background subtracted cyclic voltammogram currents were obtained by subtracting 10 cyclic voltammograms obtained before stimulation from voltammograms obtained after stimulation. After subtraction, two-dimensional voltammetric color plots were used to examine the data. To determine the time course of voltammetrically detected dopamine, the current at the peak oxidation was plotted against time. After the experiment, the electrode was calibrated using dopamine solutions of known concentration. To examine the effects of dextran on the free diffusion of dopamine, dopamine was applied by the iontophoretic application of dopamine hydrochloride as a single pulse $(100 \mathrm{nA}, 1 \mathrm{M})$ from thin-walled iontophoretic electrodes (70 to $>100$ $\mathrm{M} \Omega$ ). Iontophoretic electrodes were placed either 3 or $50 \mu \mathrm{m}$ from the tip of the carbon fiber, and a retention current of 1-5 nA was applied to prevent passive leakage. A waveform with a potential limit of $1.3 \mathrm{~V}$ and a scan rate of $400 \mathrm{~V} / \mathrm{s}$ was used.

To confirm the chemical identity of the fast-scan cyclic voltammetry (FSCV) signal, dopamine and 5-HT were applied by the iontophoretic application of either dopamine hydrochloride or serotonin hydrochloride as a single pulse (25-100 $\mathrm{nA}, 5-25 \mathrm{~ms}$, [DA] $1 \mathrm{M}$, [5-HT] $0.5 \mathrm{M})$ from thin-walled iontophoretic electrodes (70 to $>100 \mathrm{M} \Omega$ ). Iontophoretic electrodes were placed within $50 \mu \mathrm{m}$ from the tip of the carbon fiber, and a retention current of $1-5 \mathrm{nA}$ was applied to prevent passive leakage. A waveform with a potential limit of $1.3 \mathrm{~V}$ and a scan rate of $400 \mathrm{~V} / \mathrm{s}$ was used.

Materials. CGP 55845 was obtained from Tocris Bioscience. Cocaine hydrochloride was obtained from National Institute on Drug AbuseNational Institutes of Health. All other chemicals were obtained from Sigma-Aldrich.

Statistics. Data are listed are mean \pm SEM. Statistical significance was assessed with Student's $t$ tests or one-way ANOVA (Tukey post hoc analysis) where a difference of $p<0.05$ was considered significant (InStat; GraphPad Software).

\section{Results}

Comparison of the time course of the dopamine transient in the VTA, SNc, and striatum

FSCV with carbon fiber electrodes was used to compare the time course of dopamine release from axonal terminals in the dorsal striatum and dendritic terminals in the VTA. A single stimulus evoked release of dopamine in both the VTA and dorsal striatum (Fig. $1 A, B$ ). The amount of dopamine released in the midbrain was far less than that in the striatum (VTA: $47 \pm 6 \mathrm{nM}, n=10$; striatum $948 \pm 19 \mathrm{nM}, n=6 ; p<0.001$ ) (Fig. $1 A$ ), supporting previous findings (Cragg et al., 1997a). However, despite the $\sim 20$-fold greater amount of dopamine release in the striatum than VTA, the time course of the release of dopamine was similar between regions. When the two signals were normalized, the time to peak of the extracellular dopamine transients in both regions peaked within $200 \mathrm{~ms}$ of stimulation (FSCV time to peak VTA: $177 \pm 26 \mathrm{~ms}, n=10$; striatum: $133 \pm 33 \mathrm{~ms}, n=6 ; p>0.05$ ) (Fig. $1 B)$. Thus while the total amount of release varied, the rate of release was similar in the VTA and striatum. The half-width of extracellular dopamine transient was longer in the VTA than striatum (half-width VTA: $755 \pm 79 \mathrm{~ms}, n=10$; striatum: $415 \pm 40 \mathrm{~ms}, n=6 ; p<0.001$ ) (Fig. $1 B$ ). The falling phase of the dopamine transient is determined by diffusion and uptake (Schmitz et al., 2001). These results suggest that the dopamine transient is more tightly constrained in the striatum than the VTA.

Calcium dependence of release in the SNc, VTA, and striatum The dependence of release upon extracellular calcium in the VTA, SNc, and striatum was examined next. To maximize the resolution of peak concentration of extracellular dopamine $\left([\mathrm{DA}]_{\mathrm{o}}\right)$, a triangle waveform from $-0.4 \mathrm{~V}$ to $1.3 \mathrm{~V}$ and back to $-0.4 \mathrm{~V}$ at $400 \mathrm{~V} / \mathrm{s}$ was used. A single stimulus was used to evoke dopamine release in the striatum and trains of 5 stimuli $(40 \mathrm{~Hz})$ were used in the VTA and SNc. Dopamine release in both the midbrain and striatum exhibited a strong dependence upon extracellular calcium $\left(\left[\mathrm{Ca}^{2+}\right]_{\mathrm{o}}\right)$. Reducing extracellular calcium from $2.4 \mathrm{~mm}$ to $0.5 \mathrm{~mm}$ inhibited the amount of dopamine de- 
A

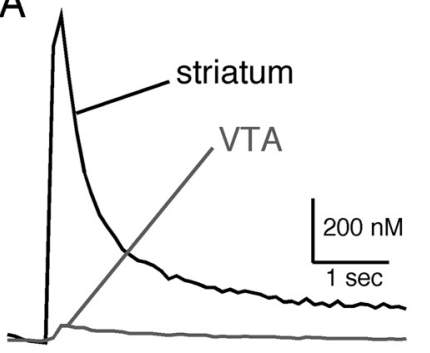

B

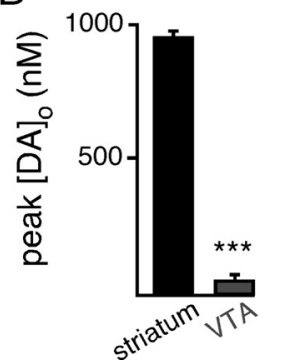

normalized

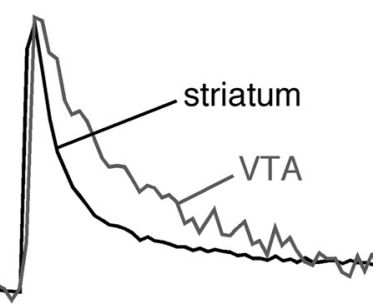

A VTA FSCV

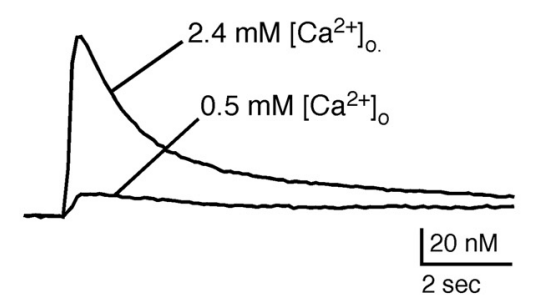

B SNC FSCV

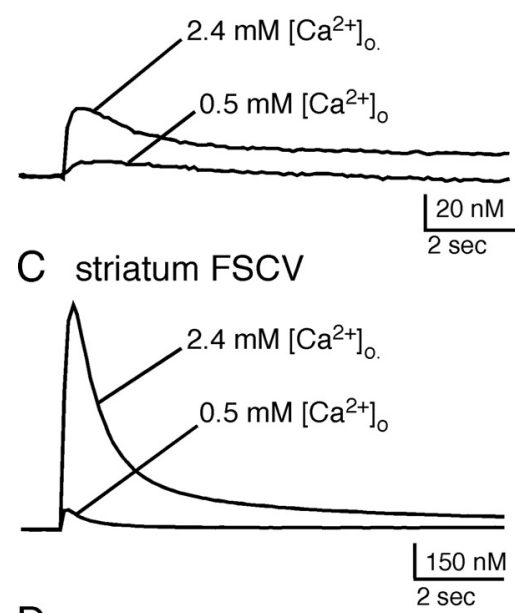

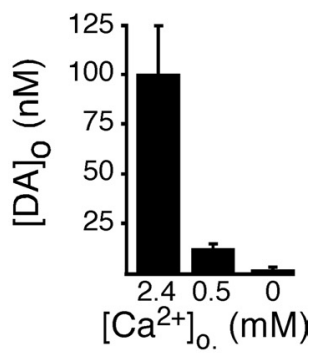

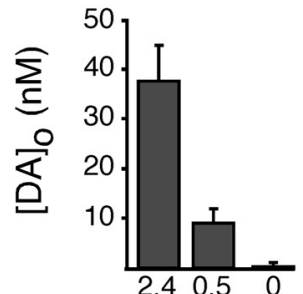

$\left[\mathrm{Ca}^{2+}\right]_{0}(\mathrm{mM})$

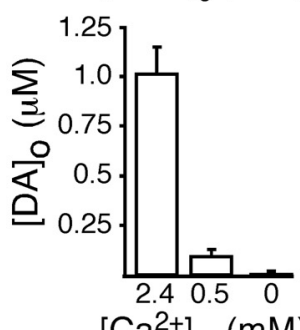

Figure 1. A single stimulus evoked more dopamine release in the striatum than the VTA, yet the time course of release is similar. $\boldsymbol{A}$, A single stimulation was used to evoke dopamine release in the VTA ( $n=10$; gray trace) and the dorsal striatum ( $n=6$; black trace). A single stimulation produced $\sim 20$-fold more dopamine release in the striatum than the VTA. After normalizing the dopamine transients, the time to peak of the two signals both occurred within $200 \mathrm{~ms}$. The duration of the signal was longer in the VTA than the striatum. Error bars have been omitted for clarity. $\boldsymbol{B}$, Summarized data illustrating the peak concentration of the dopamine transient, the time to peak of the dopamine transient, and the half-width of the dopamine transient in the VTA and striatum. ${ }^{* *} p<0.01,{ }^{* * *} p<0.001$.

tected in the extracellular space to a similar extent at all sites examined. With low $\left[\mathrm{Ca}^{2+}\right]_{\mathrm{o}}(0.5 \mathrm{~mm})$, dopamine release was reduced to $12 \pm 2 \%(p<0.01 ; n=6)$ in the VTA, $20 \pm 5 \%(p<$ $0.01 ; n=6)$ in the SNc, and $10 \pm 3 \%(p<0.01 ; n=6)$ in the striatum (Fig. $2 A-C$ ). Removal of extracellular calcium led to the complete block of dopamine release in the VTA, SNc, and the striatum after $10 \mathrm{~min}$ (Fig. $2 A-C$ ). To further characterize the calcium dependence of release, FSCV measurements were made in the SNc, VTA, and striatum over a wider range of extracellular $\mathrm{Ca}^{2+}$ concentrations in a separate group of slices (Fig. 2D). To compare between groups, the presence of extracellular dopamine was normalized to the maximum response recorded at $2.4 \mathrm{~mm}$ $\left[\mathrm{Ca}^{2+}\right]_{\mathrm{o}}$ in each region. Reducing the $\left[\mathrm{Ca}^{2+}\right]_{\mathrm{o}}$ to either $1.5 \mathrm{~mm}$ or $1.0 \mathrm{~mm}$ led to a sequential decrease in the amount of dopamine released. At both $1.5 \mathrm{~mm}$ or $1.0 \mathrm{~mm}\left[\mathrm{Ca}^{2+}\right]_{\mathrm{o}}$, release was inhibited to a similar extent in the SNc, VTA, and striatum (Fig. 2D). Further lowering $\left[\mathrm{Ca}^{2+}\right]_{\mathrm{o}}$ to $0.5 \mathrm{~mm}$ led to a further inhibition of release at all sites. A statistically greater inhibition occurred in the striatum than the midbrain (VTA: $14 \pm 3 \%, n=10$; SNc: $17 \pm$ $2 \%, n=9$; striatum $8 \pm 2 \%, n=9 ; p<0.05$ striatum vs $\mathrm{SNc} ; p<$ 0.05 VTA vs striatum; $p>0.05$ VTA vs SNc; one-way ANOVA Student-Newman-Keuls multiple-comparison test) (Fig. 2D). This difference at $0.5 \mathrm{~mm}\left[\mathrm{Ca}^{2+}\right]_{\mathrm{o}}$, however, should be viewed with caution because of the difficulty in accurately measuring low levels of dopamine ( $<15 \mathrm{nM}$ ) that remained after switching to 0.5 $\mathrm{mM}\left[\mathrm{Ca}^{2+}\right]_{\mathrm{o}}$ in the midbrain. Overall, these results indicate that dopamine release exhibits a strong dependence on $\left[\mathrm{Ca}^{2+}\right]_{\mathrm{o}}$ at both axonal and dendritic release sites.

The calcium dependence of the $\mathrm{D}_{2}$-IPSC resulting from dendritic release of dopamine was next compared to the results obtained using FSCV. $\mathrm{D}_{2}$-IPSCs and the extracellular presence of dopamine were simultaneously measured in the VTA (Fig. 3A).

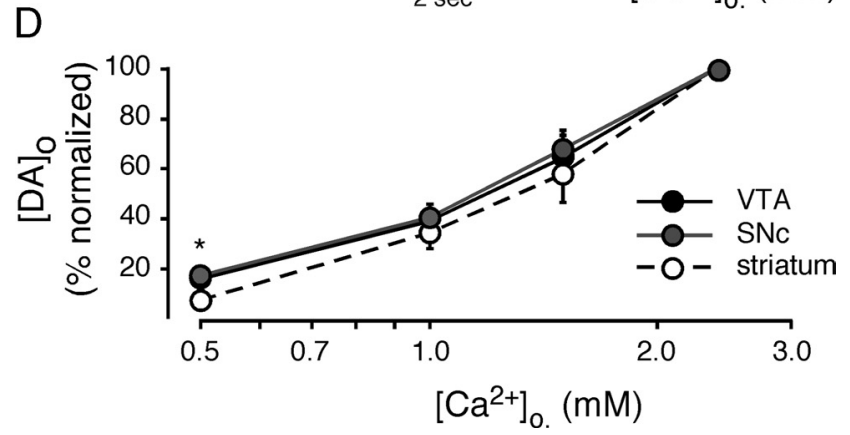

Figure 2. Dopamine release in the VTA, SNc, and striatum exhibit similar dependences upon extracellular calcium. $\boldsymbol{A}-\boldsymbol{C}$, Dopamine release in the VTA $(\boldsymbol{A})$, SNc $(\boldsymbol{B})$, and striatum $(\boldsymbol{C})$ were compared in $2.4,0.5$, and $0 \mathrm{~mm}\left[\mathrm{Ca}^{2+}\right]_{0}$ solutions. A train of 5 stimuli was used to evoke release in the VTA and SNc, while a single stimulus was used to evoke release in the striatum. Experiments were initiated in $2.4 \mathrm{~mm}\left[\mathrm{Ca}^{2+}\right]_{0}$ solution, followed by a $10 \mathrm{~min}$ application of $0.5 \mathrm{~mm}$ $\left[\mathrm{Ca}^{2+}\right]_{0}$ solution and a $10 \mathrm{~min}$ application of $0 \mathrm{~mm}\left[\mathrm{Ca}^{2+}\right]_{0}$ solution. $n=6$ for all bars. The FSCV waveform used was from $-0.4 \mathrm{~V}$ to $1.3 \mathrm{~V}$ at $400 \mathrm{~V} / \mathrm{s}$. D, Normalized dopamine release in the VTA, SNc, and striatum in $0.5,1.0,1.5$, and $2.4 \mathrm{~mm}\left[\mathrm{Ca}^{2+}\right]_{0}$. The normalized amount of dopamine in the extracellular space was similar in all conditions, except $0.5 \mathrm{~mm}\left[\mathrm{Ca}^{2+}\right]_{0}$, where a greater amount of dopamine could be detected in the VTA and SNc than the striatum. ${ }^{*} p<0.05$ (Student-Newman-Keuls test), $n=6-10$ for all points illustrated.

Following a train of 5 stimuli, the increase $[\mathrm{DA}]_{\mathrm{o}}$ preceded the IPSC. The peak of the $[\mathrm{DA}]_{\mathrm{o}}$ occurred $\sim 130 \mathrm{~ms}$ before the peak of the $\mathrm{D}_{2}$-IPSC, indicative of the time required for activation of the $\mathrm{D}_{2}$ receptor/G-protein/GIRK channel cascade (Ford et al., 2009). Removing extracellular calcium dramatically reduced the amplitude of both the $\mathrm{D}_{2}$-IPSC by $94 \pm 2 \%(n=8 ; p<0.001)$ and the change in extracellular dopamine measured by FSCV by $90 \pm 2 \%(n=8 ; p<0.001)$ (Fig. 3A). This indicates that in the midbrain, dopamine release does not persist following the removal of extracellular calcium.

In the guinea pig, the release of calcium from intracellular stores facilitates the somatodendritic release of dopamine (Patel 
et al., 2009). To examine whether calcium release from intracellular stores facilitates dendritic dopamine release in mice, the effect of the SERCA inhibitor cyclopiazonic acid (CPA) was examined. In the VTA, a 10 min perfusion of CPA $(30 \mu \mathrm{M})$ failed to alter dopamine-mediated $\mathrm{D}_{2}$ IPSCs ( $101 \pm 5 \%$ of control, $p>0.05 ; n=$ $5)$, or the rise in extracellular dopamine measured with FSCV $(99 \pm 3 \%$ of control, $p>0.05 ; n=5$ ) (Fig. 3B). Likewise CPA $(30 \mu \mathrm{M})$ failed to alter the amplitude of $\mathrm{D}_{2}$-IPSCs or the extracellular presence of dopamine evoked by a long train of stimuli (30 stimuli, $10 \mathrm{~Hz}$. $\mathrm{D}_{2}$-IPSC: $102 \pm 6 \%$ of control, $n=4, p>0.05$; [DA ] $]_{\mathrm{o}}: 96 \pm$ $3 \%$ of control, $n=10, p>0.05$; data not shown). As a positive control to verify the effectiveness of CPA to block the mobilization of intracellular calcium, CPA (30 $\mu \mathrm{M})$ was examined on inositol 1,4,5triphosphate $\left(\mathrm{IP}_{3}\right)$-mediated small-conductance $\mathrm{Ca}^{2+}$-activated $\mathrm{K}^{+}$channel (SK channel) currents in dopamine cells. Whole-cell recordings were made from dopamine neurons that were dialyzed with caged $\mathrm{IP}_{3}(100 \mu \mathrm{M})$. The release of $\mathrm{IP}_{3}$, evoked by photo-uncaging with a pulse of light $(5 \mathrm{~ms})$, resulted in an apamin-sensitive SK outward current (Morikawa et al., 2000). The $\mathrm{IP}_{3}$-mediated SK current was completely inhibited by CPA ( $10 \mu \mathrm{M}, 3 \mathrm{~min}$, data not shown), confirming the effectiveness of CPA in depleting intracellular stores. The results indicate that dopamine release in the midbrain of the mouse (whether measured with electrochemistry or electrophysiology) is dependent on calcium entry and under these conditions does not rely on the mobilization of calcium from intracellular pools.

\section{Despite differences in the total amount of dopamine release in the VTA and SNc, transmission is similar}

As reported previously (Rice et al., 1994, 1997; Cragg et al., 1997b), the total amount of dopamine released in the VTA was greater than in the SNc (Fig. 2A,B). This may be due to a greater density of dopamine cells in the VTA than in the SNc (German and Manaye, 1993) or to the presence of axon collaterals in the VTA contributing to additional dopamine release (Geffen et al., 1976; Juraska et al., 1977; Bayer and Pickel, 1990; Nirenberg et al., 1996). As separate slices were used in the previous experiments, it was not possible to directly compare dopamine release in the VTA and SNc. The relative amplitude of the increase in extracellular dopamine recorded with FSCV was next compared directly with $\mathrm{D}_{2}$-IPSCs in both the VTA and SNc within the same slice. A FSCV waveform from $-0.4 \mathrm{~V}$ to 1.3 $\mathrm{V}$ at $400 \mathrm{~V} / \mathrm{s}$ was used to maximize resolution. A train of stimuli (5 stimuli at $40 \mathrm{~Hz}$ ) evoked greater dopamine release in the VTA $(171 \pm 16 \mathrm{nM}, n=13)$ than the SNc $(61 \pm 4 \mathrm{nM}, n=11 ; p<0.001)$ (Fig. 4). Despite a greater amount of dopamine released in the VTA, $\mathrm{D}_{2}$-IPSCs exhibited a similar amplitude and time course in the VTA (amplitude: $199 \pm 18 \mathrm{pA}$, time to peak: $380 \pm 13 \mathrm{~ms} ; n=13$ ) and SNc (amplitude: $234 \pm 30 \mathrm{pA}$, time to peak $386 \pm 21 \mathrm{~ms} ; n=11 ; p>$ $0.05)$ (Fig. 4). These results demonstrate that although the amount of dopamine measured in the extracellular solution varied across the midbrain, the time course and amplitude of dopamine IPSCs did not. This suggests that the strength of transmission remained conserved across the midbrain.

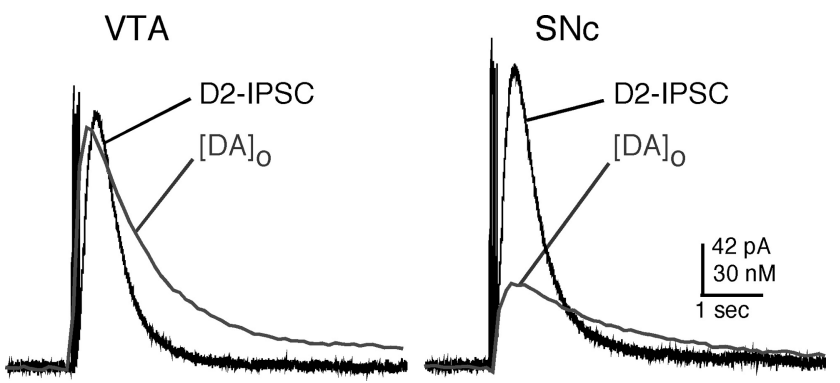

Figure 4. Dopamine IPSCS in the VTA and SNc are similar despite a greater extracellular presence of dopamine in the VTA. Example traces illustrating simultaneous recordings of [DA] and $\mathrm{D}_{2}$-IPSCs in the VTA and SNc. A train of 5 stimuli produced IPSCS of similar amplitude and duration in both the VTA and $S \mathrm{Nc}$, yet the $[D A]_{0}$ evoked from by the same stimulation was greater in the VTA than in the SNC. FSCV was used to measure $[D A]_{0}$.

\section{Pharmacological and electrochemical characterization of signals in the VTA and SNc}

The midbrain of rats and mice receives innervation by serotonergic fibers (Rice et al., 1994; Cragg et al., 1997b; John et al., 2006). As both dopamine and serotonin $(5-\mathrm{HT})$ can be detected with cyclic voltammetry, it was possible that FSCV measured both 5-HT and dopamine. The chemical identity of the catecholamines in the midbrain was determined by comparing voltammograms (oxidation-reduction profiles) from exogenously applied dopamine or serotonin to voltammograms obtained from evoked release in the VTA and SNc (Fig. 5A). Dopamine and 5-HT have different reduction peaks (Stamford, 1990; Kawagoe et al., 1993; Rice et al., 1994; Michael and Wightman, 1999; Zhou et al., 2005; John et al., 2006). The peak reduction potential of exogenously applied dopamine was $-351 \mathrm{mV}$ (Fig. 5A). This peak matched well with the reduction peak obtained recorded after evoking release in the VTA $(-349 \mathrm{mV}, 5 \mathrm{stim}, 40 \mathrm{~Hz} ; n=9$ slices), confirming the chemical identity of dopamine (Fig. $5 A$ ). Evoking release in the $\mathrm{SNc}$ produced a voltammogram with two separate reduction peaks, one at $-325 \mathrm{mV}$ and a second at -172 
A
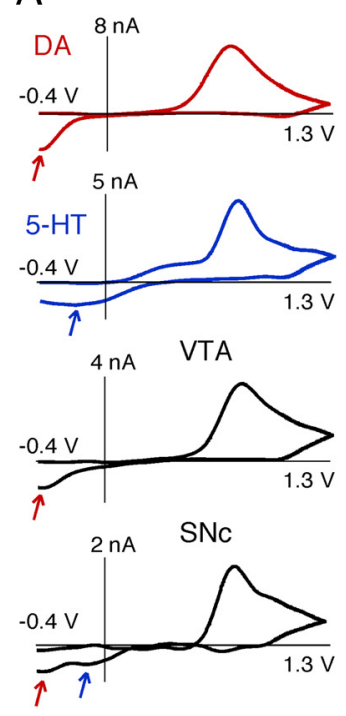

B

B FSCV (VTA)
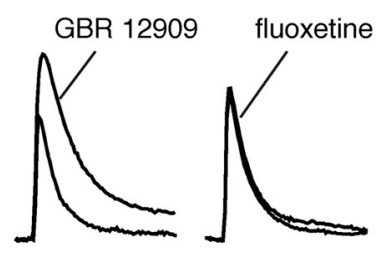

FSCV (SNc)

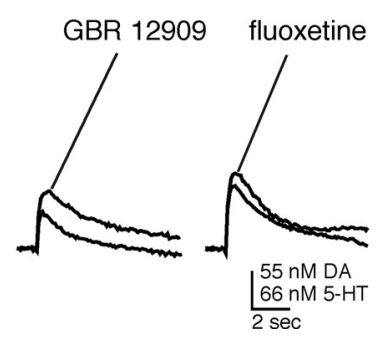

C D2-IPSC (VTA)

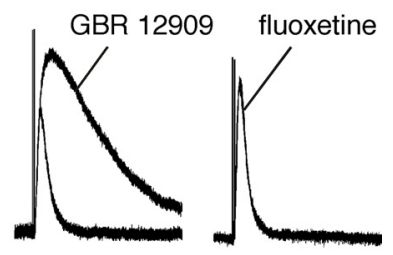

D2-IPSC (SNc)

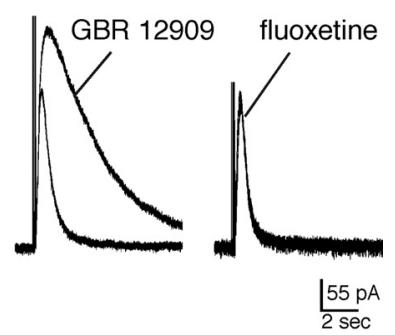

Figure 5. Electrochemical and pharmacological characterization of catecholamine release in the midbrain. $A$, FSCV waveforms $(-0.4$ to $1.3 \mathrm{~V}$ at $400 \mathrm{~V} / \mathrm{s})$ revealed that the voltammogram for exogenously applied DA (red trace) had a reduction peak ( -351 $\mathrm{mV}$, red arrow) that matched that of the signal recorded upon evoking release in the VTA by a train of stimuli ( 5 pulses, $0.5 \mathrm{~ms}, 40$ $\mathrm{Hz})(-349 \mathrm{mV})$. A similar train of stimuli in the SNc produced a voltammogram with two reduction peaks, one similar to dopamine ( $-325 \mathrm{mV}$, red arrow) and the other similar to 5-HT ( $-172 \mathrm{mV}$, blue arrow, vs $-182 \mathrm{mV}$ for exogenously applied 5-HT, blue trace). Thus only dopamine was detected in the VTA, but both dopamine and 5-HT were detected in the SNc. B, Representative FSCV traces illustrating the increase in the FSCV signal in both the VTA and SNC after blocking DAT with GBR 12909 ( $1 \mu \mathrm{M})$. There was no effect of the SERT blocker fluoxetine (1 $\mu \mathrm{m})$ in the VTA and only a slight potentiation of the FSCV signal in the SNc.C, Representative $D_{2}$-IPSCs illustrating the increase in charge transfer after blocking DAT with GBR $12909(1 \mu \mathrm{M})$ in both the VTA and SNc. Blocking SERT with fluoxetine $(1 \mu \mathrm{m})$ had no effect.

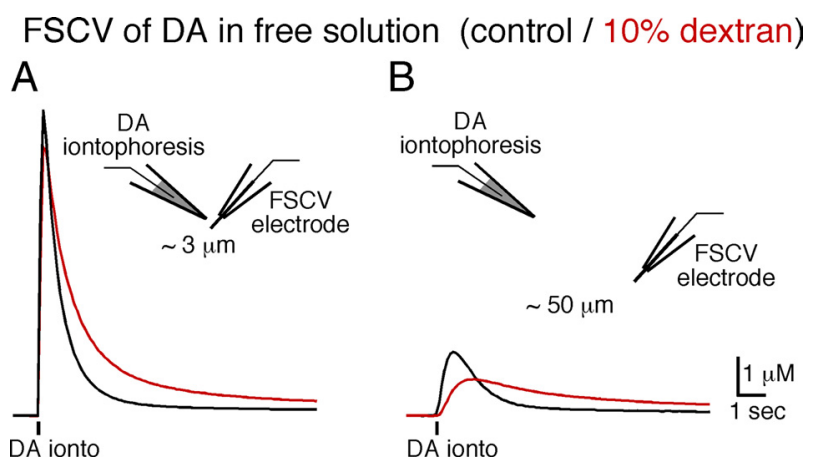

Figure 6. Extracellular dextran slows the free diffusion of dopamine. FSCV measurement of free dopamine in solution. Dopamine was applied by iontophoresis onto a carbon fiber and detected using FSCV with a voltage waveform of -0.4 to $1.3 \mathrm{~V}$ at $400 \mathrm{~V} / \mathrm{s}$. Dopamine was ejected onto carbon fibers in control solution (black) and in a dextran-containing solution ( $10 \%$ $\mathrm{w} / \mathrm{v}, \mathrm{red}) . \boldsymbol{A}, \boldsymbol{B}$, Representative traces where dopamine was ejected onto the carbon fiber from a distance of $\sim 3 \mu \mathrm{m}(\boldsymbol{A})$ or $\sim 50 \mu \mathrm{m}(\boldsymbol{B})$. Dextran thus slowed the time to peak and increased the duration of the dopamine transient as a function of distance.

$\mathrm{mV}(n=6$ slices) (Fig. $5 A)$. The first reduction peak matched that of dopamine, and the second peak matched that obtained from the exogenous application of 5-HT $(-182 \mathrm{mV})$ (Fig. 5A), indicating that both dopamine and 5-HT were released in the SNc.

We next examined the ability of specific blockers of DAT and serotonin transporter (SERT) to alter the presence of dopamine and 5-HT in the midbrain. The DAT blocker GBR $12909(1 \mu \mathrm{M})$ potentiated the voltammetric signal in both the VTA $(344 \pm 62 \%$ of control; $n=6 ; p<0.005)$ and the SNc (306 $\pm 78 \%$ of control; $n=7 ; p<0.05$ ) (Fig. $5 B$ ), confirming the release of dopamine across the midbrain. Likewise, GBR 12909 increased the total

charge transfer of the IPSC in both the VTA $(588 \pm 102 \%$ of control; $n=5 ; p<$ $0.01)$ and the SNc (477 $\pm 98 \%$ of control, $n=5 ; p<0.05$ ) (Fig. $5 C$ ). The SERT blocker, fluoxetine $(1 \mu \mathrm{M})$ had no effect on $\mathrm{D}_{2}$-IPSCs in either the VTA $(n=5 ; p>$ $0.05)$ or the SNc $(n=4 ; p>0.05)$, despite increasing the FSCV signal detected in the $\mathrm{SNc}(130+13 \%$ of control; $n=6 ; p<$ $0.05)$. Fluoxetine had no effect on the voltammetric signal recorded in the VTA $(n=6 ; p>0.05)$. Thus DAT is responsible for terminating both the IPSC and the extracellular presence of dopamine across the midbrain. These results indicate that in the VTA only dopamine could be detected. However, in the SNc, both dopamine and a minor presence of 5-HT could be detected. Thus the FSCV measurements in the VTA represent only the release of dopamine, while measurements in the SNc may represent the combination of 5-HT and dopamine.

\section{Dopamine diffusion and uptake in the midbrain and the striatum}

Clearance of extracellular dopamine is dependent on the combination of diffusion and reuptake. The relative contribution of these two mechanisms to the time course of the dopamine transient was further examined in the striatum and VTA. The diffusion of dopamine in free solution was slowed by the addition of dextran to the extracellular solution $(10 \%, 40 \mathrm{kDa})$. Dopamine was applied by iontophoresis at different distances away from the FSCV carbon fiber, and the duration was compared in the absence and presence of the dextran-containing solution. When the tip of the iontophoretic electrode was within $\sim 3 \mu \mathrm{m}$ of the carbon fiber, dextran increased the duration of the dopamine transient at the carbon fiber to $156 \pm 17 \%$ of control halfwidth $(n=6, p<0.01)$. When dopamine was iontophoresed from a distance of $3 \mu \mathrm{m}$, dextran did not alter the latency to onset or the peak concentration of dopamine $(n=6, p>0.05)$ (Fig. 6A), indicating that dextran did not have a significant effect on the electrochemical detection of dopamine. As the iontophoretic electrode was moved farther from the carbon fiber, the amplitude and the time course of the rise and fall of dopamine were reduced in the presence of dextran. When the iontophoretic electrode was $\sim 50 \mu \mathrm{m}$ from the carbon fiber, the peak concentration of dopamine was decreased to $48 \pm 9 \%$ of control $(n=6, p<0.01)$, the time to peak increased to $200 \pm 15 \%$ of control $(n=6, p<0.001)$, and the duration increased to $350 \pm 42 \%$ of control $(n=6, p<0.0001)$ (Fig. $6 B)$. This indicates that dextran slowed the free diffusion of dopamine and altered the kinetics of the extracellular dopamine transient as a function of distance.

The kinetics of the dopamine transient evoked by electrical stimulation in the striatum and VTA was next examined in the absence and presence of the dextran-containing solution. Due to the slow penetration of the dextran, brain slices were preincubated in the dextran solution for $\geq 1 \mathrm{~h}$ before recording, and separate slices were compared. A train of 5 stimuli $(40 \mathrm{~Hz})$ was used to evoke release in both the VTA and striatum. The $\mathrm{D}_{2}$ 
receptor antagonist, sulpiride (200 nM) was included in the extracellular solution in all cases to prevent $\mathrm{D}_{2}$ autoreceptor activation. In the VTA, the kinetics of the rise and fall of the dopamine transient measured with FSCV were significantly slowed in the dextran solution (Fig. 7A). The time to peak of the dopamine transient in the VTA increased to $185 \%$ of control (control: $258 \pm 31 \mathrm{~ms}, n=12$; dextran: $506 \pm 46 \mathrm{~ms}, n=16$; $p<0.001$ ), and the half-width increased to $200 \%$ of control (control: $1.2 \pm 0.2 \mathrm{~s}, n=12$; dextran: $2.4 \pm 0.3 \mathrm{~s}, n=16 ; p<0.001$ ) (Fig. $7 B)$. The peak concentration of dopamine in dextran-treated slices also decreased to 48\% of control (control: $95 \pm 16 \mathrm{nM}, n=$ 12; dextran: $50 \pm 8 \mathrm{nM}, n=16, p<0.05$ ) (Fig. $7 B$ ). Thus in the VTA dopamine diffuses over extended distances from the site of release before reaching the carbon fiber.

In the striatum, dextran reduced the peak concentration of dopamine (control: $1.9 \pm 0.2 \mu \mathrm{M}, n=11$; dextran: $1.0 \pm 0.1$ $\mu \mathrm{M}, n=12$; $p<0.05$ ); however, the kinetics of the dopamine transient were not significantly affected (time to peak control: $227 \pm 14 \mathrm{~ms}, n=11$; time to peak dextran: $300 \pm 21 \mathrm{~ms}, n=12 ; p>0.05$ ) (Fig. $7 C, D)$. Thus unlike the VTA, the dextran solution did not significantly alter the time course of the dopamine transient in the striatum, confirming that diffusion of dopamine is more tightly constrained near the site of release when compared with the VTA.

Due to the slow penetration of GBR 12909 into the slice, the role of transporters in the VTA and striatum was examined using the monoamine blocker cocaine $(1 \mu \mathrm{M})$. As expected, in both the VTA and striatum, cocaine $(1 \mu \mathrm{M})$ increased the peak concentration and slowed the kinetics of the dopamine transient (Fig. $7 A, C)$. Cocaine $(1 \mu \mathrm{M})$ increased the peak concentration of dopamine in the VTA to $174 \%$ of control (control: $95 \pm 16 \mathrm{nM}, n=$ 12; cocaine: $166 \pm 35 \mathrm{nM}, n=11, p<0.01)$ and to $149 \%$ of control in the striatum (control: $1.9 \pm 0.2 \mu \mathrm{M}, n=11$; cocaine: $2.8 \pm 0.2 \mu \mathrm{M}, n=12, p<0.05)$. Likewise cocaine $(1 \mu \mathrm{M})$ increased the time to peak of the dopamine transient in the VTA to 183\% of control (control: $258 \pm 31 \mathrm{~ms}, n=12$; cocaine: $518 \pm 70$ $\mathrm{ms}, n=11 p<0.01)$ and to $226 \%$ of control in the striatum (control: $227 \pm 14 \mathrm{~ms}, n=11$; cocaine: $473 \pm 34 \mathrm{~ms}, n=12 ; p<$ $0.01)$. The half-width of the dopamine transient was increased to $206 \%$ of control in the VTA (control: $1.2 \pm 0.2 \mathrm{~s}, n=12$; cocaine: $2.5 \pm 0.3 \mathrm{~s}, n=11 ; p<0.01)$ and to $180 \%$ of control in the striatum (control: $700 \pm 58 \mathrm{~ms}, n=11$; cocaine: $1.4 \pm 0.1 \mathrm{~s}$, $n=12 ; p<0.01)$. These results suggest that dopamine transporters regulate the presence of dopamine in both the striatum and VTA, and confirm that diffusion of dopamine is more tightly regulated by transporters in the striatum than in the VTA (Cragg et al., 1997a).

\section{The dopamine IPSC is mediated by $D_{2}$ receptors that are located near the site of release}

Given that diffusion of extracellular dopamine was slowed by dextran in the VTA, the kinetics of the $\mathrm{D}_{2}$-IPSC also were ex-
B
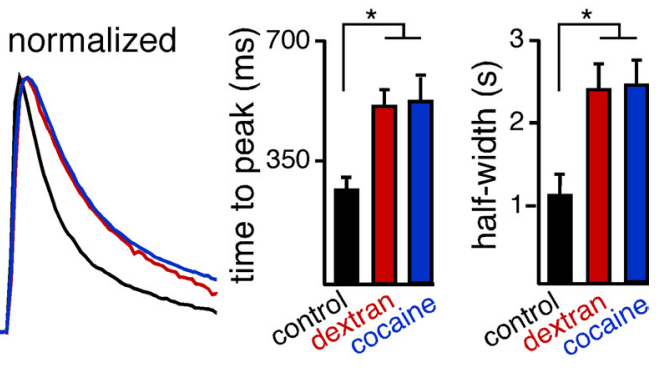

D
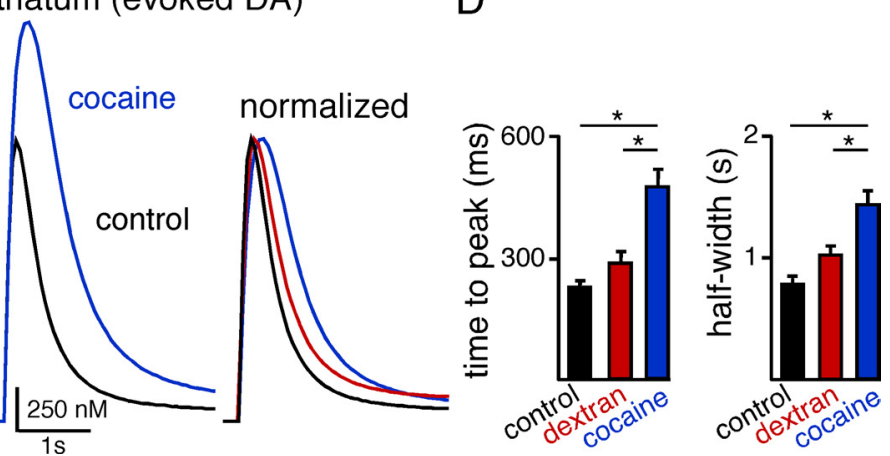

Diffusion and uptake regulate the extracellular presence of dopamine in the VTA and striatum. $A, C, F S C V$ measure-

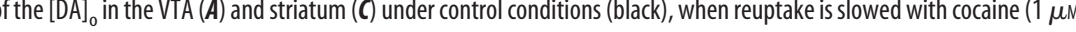
and striatum, cocaine slowed the rise and fall in the dopamine transient, yet only in the VTA did dextran slow the kinetics of the $[\mathrm{DA}]_{0} \cdot{ }^{*} p<0.05$, one-way ANOVA (Tukey test).

pected to slow in the presence of dextran. Surprisingly, however, the kinetics of the $\mathrm{D}_{2}$-IPSC did not change by the addition of dextran to the extracellular solution (Fig. 8A). The amplitude, time to peak, and half-width of $\mathrm{D}_{2}$-IPSCs were the same in control and dextran solutions (control amplitude: $36 \pm 4 \mathrm{pA}, n=12$; dextran: $33 \pm 5 \mathrm{pA}, n=12 ; p>0.05$; time to peak control: $320 \pm$ $7 \mathrm{~ms}, n=12$; dextran: $346 \pm 11, n=12, p>0.05$; half-width control: $89 \pm 26 \mathrm{~ms}, n=11$; dextran: $96 \pm 34 \mathrm{~ms}, n=12, p>$ 0.05 ) (Fig. $8 A, B$ ). As a positive control, in the same slices where dextran failed to alter the dopamine IPSC, the outward current induced by iontophoretic application of dopamine was dramatically slowed (time to peak control: $625 \pm 44 \mathrm{~ms}, n=16$; dextran: $1093 \pm 61, n=14, p<0.001$; half-width control: $870 \pm 47 \mathrm{~ms}$, $n=15$; dextran: $1325 \pm 115 \mathrm{~ms}, n=13, p<0.05)$ (Fig. $8 A, C$ ). The outward current evoked by iontophoretic application of dopamine has a longer latency and slower kinetics than the IPSC (Beckstead et al., 2004). This is because the location of the iontophoretic tip is further from $\mathrm{D}_{2}$ receptors than the point of dopamine release mediating the IPSC (Beckstead et al., 2004). As the $\mathrm{D}_{2}$-IPSC was insensitive to the effects of dextran, these results indicate that synaptically released dopamine does not diffuse over extended distances before binding to $\mathrm{D}_{2}$ receptors. Thus, postsynaptic $\mathrm{D}_{2}$ receptors are localized near the site of dopamine release.

Finally, as reported previously (Beckstead et al., 2004; Ford et al., 2006, 2009), cocaine ( $1 \mu \mathrm{M})$ increased the amplitude and time course of the $\mathrm{D}_{2}$-IPSC as well as the outward current evoked by iontophoretic application of dopamine (Fig. $8 \mathrm{~A}, \mathrm{C}$ ). Thus, transporters tightly regulate the presence of dopamine at postsynaptic receptors during transmission. 


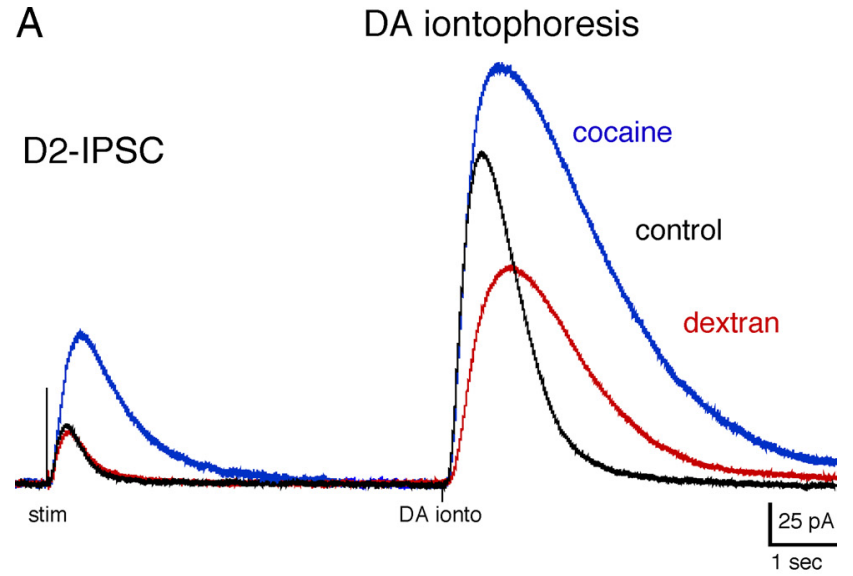

B

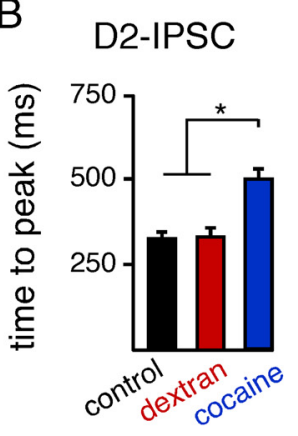

C DA iontophoresis
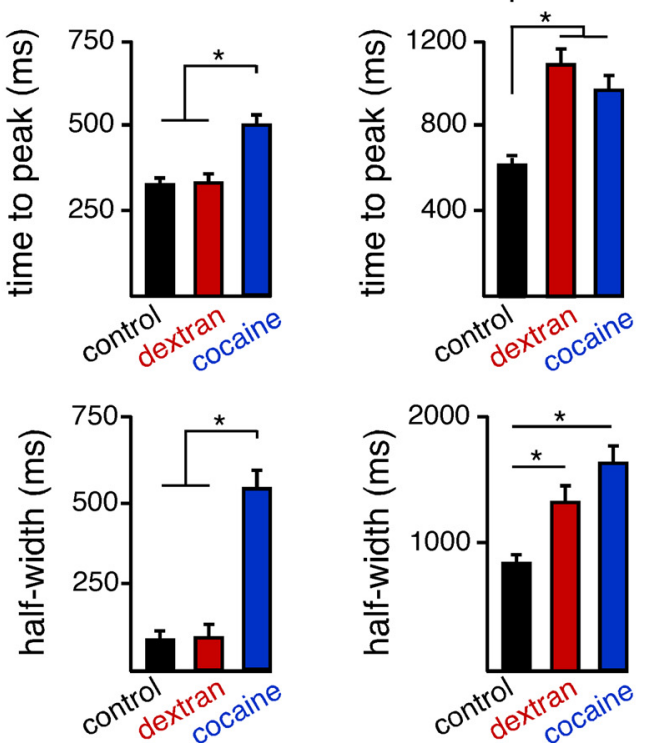

Figure 8. Slowing the diffusion of dopamine did not alter the $D_{2}$-IPSC. $A$, Representative traces illustrating single stimulation-evoked $D_{2}$-IPSCS and the current evoked by the iontophoretic application of dopamine under control conditions (black) and in the presence of dextran (10\%) (red) and cocaine (1 $\mu \mathrm{m}$ ) (blue). Note the lack of effect of dextran on $\mathrm{D}_{2}$-IPSCS, yet the increase in amplitude, time to peak, and half-width in the presence of cocaine. The current evoked by the iontophoresis of dopamine, however, is diminished and slowed in the presence of dextran and increased and slowed in the presence of cocaine. $\boldsymbol{B}$, Summarized data illustrating the time to peak and half-width of $D_{2}$-IPSCS in the above conditions. $C$, Summarized data illustrating the time to peak and half-width for the currents evoked by the iontophoretic application of dopamine. ${ }^{*} p<0.05$, one-way ANOVA (Tukey test).

\section{Discussion}

Midbrain dopamine neurons of the VTA and SNc project to multiple forebrain regions to modulate goal-oriented behaviors and movement. Dysregulation of dopamine transmission underlies a variety of psychiatric and movement disorders, ranging from Parkinson's disease to schizophrenia, attention-deficit hyperactivity disorder, and drug addiction (Madras et al., 2005; Iversen, 2006; Meisenzahl et al., 2007). Somatodendritic release of dopamine release in the substantia nigra and VTA inhibits the activity of dopamine neurons and therefore the subsequent release of dopamine in terminal regions (Lacey et al., 1987; Pucak and Grace, 1994). With the combination of electrochemistry and electrophysiology, dendritic dopamine release in the VTA and SNc was compared directly with release from axonal terminals in the stria- tum. The results indicate that dopamine release from axons and dendrites was similar in time course and dependence on extracellular calcium. Thus, transmission in the midbrain may be more analogous to that at terminal regions in the forebrain than previously believed.

\section{Dendritic and terminal release}

Dendritic release of dopamine has been reported to persist in low $\left[\mathrm{Ca}^{2+}\right]_{\mathrm{o}}$ solutions $(0-0.5 \mathrm{~mm})$ (Hoffman and Gerhardt, 1999; Chen and Rice, 2001; Chen et al., 2006), leading to the conclusion that minimal calcium entry is required for dendritic release. The present results challenge this conclusion. The release of dopamine showed a strong dependence on extracellular calcium at both axonal and dendritic sites over a wide range of $\left[\mathrm{Ca}^{2+}\right]_{\mathrm{o}}$. Lowering $\left[\mathrm{Ca}^{2+}\right]_{\mathrm{o}}$ to $0.5 \mathrm{~mm}$ reduced the amount of dopamine release at all sites examined. Removing extracellular calcium eliminated both dopamine release and $\mathrm{D}_{2}$-IPSCs. In rats and mice, $\mathrm{Cd}^{2+}$ and $\mathrm{N}$ - and T-type voltage-gated calcium channel blockers inhibit somatodendritic dopamine release (Jaffe et al., 1998; Beckstead et al., 2004; Ford et al., 2007). The present results also suggest that dendritic dopamine release shows a strong dependence on external calcium entry. Thus, like dopamine release from axons, where calcium entry occurs primarily through $\mathrm{N}$ and P/Q-type channels (Phillips and Stamford, 2000; Chen et al., 2006), dendritic dopamine release in the mouse also depends on voltage-gated calcium channels. This differs from somatodendritic dopamine release in the guinea pig, where calcium entry through calcium channels plays a reduced role (Chen et al., 2006).

A recent report indicated that calcium release from $\mathrm{IP}_{3}$ and ryanodine receptor-sensitive intracellular stores facilitated somatodendritic release of dopamine (Patel et al., 2009). As the activation of group 1 metabotropic glutamate receptors (mGluR1) in dopamine cells results in the generation of $\mathrm{IP}_{3}$ and the subsequent mobilization of $\mathrm{Ca}^{2+}$ from intracellular stores (Fiorillo and Williams, 1998; Morikawa et al., 2000), the activation of mGluR1 receptors was also found to facilitate the release of dopamine in the SNc (Patel et al., 2009). This mechanism, however, does not appear to contribute to the release of dopamine under the present conditions. Despite the complete inhibition of $\mathrm{IP}_{3}$-mediated activation of SK current with the SERCA inhibitor CPA, there was no change in somatodendritic release of dopamine measured with FSCV or the $\mathrm{D}_{2}$-IPSC either during brief trains ( 5 stimuli at $40 \mathrm{~Hz}$ ), or prolonged stimulation $(30$ stimuli at $10 \mathrm{~Hz}$ ). Thus blocking the release of calcium from intracellular stores failed to alter somatodendritic dopamine release. Additionally, the release of dopamine that underlies the $\mathrm{D}_{2}$-IPSC peaks in $<100 \mathrm{~ms}$, whereas the release of calcium from intracellular stores following mGluR1 activation has a latency of $\sim 300 \mathrm{~ms}$ (Fiorillo and Williams, 1998; Morikawa et al., 2000). Thus, the release of dopamine that underlies the $\mathrm{D}_{2}$-IPSC most likely occurs well before the mGluR-mediated rise in intracellular calcium. Therefore, although the release of calcium from intracellular stores may facilitate dopamine release under certain conditions during periods of prolonged stimulation, this mechanism does not contribute to dopamine release in the midbrain during phasic activation observed here.

\section{Diffusion and reuptake}

Dopamine has been reported to rise and fall with $\sim 15$-fold slower kinetics in the SNc than in the striatum (Chen and Rice, 2001). The extended presence of dopamine has been interpreted to result in paracrine, or volume-based, transmission. In the mid- 
brain, $[\mathrm{DA}]_{\mathrm{o}}$ peaked with the same latency as in the dorsal striatum. There was less than a twofold difference in the halfwidth of dopamine transient in the midbrain compared with that in the striatum. This small difference most likely represents an increase in the total number of dopamine transporters in the striatum. The major difference between the VTA and striatum was the total amount of dopamine released. While the difference in release may possibly reflect differences in the loading of vesicles in terminals versus dendrites, it more likely reflects the higher density of release sites in the striatum. The present study indicates that release of dopamine from axon and dendrites occurs with a similar time course. Thus these results indicate that the rise and fall of dopamine following release from dendrites is faster and more analogous to that from axons than previously believed.

The time course of the dopamine transient following release was examined after partially blocking uptake with cocaine and slowing diffusion with the addition of dextran. Through molecular overcrowding, high concentrations of dextran $(10 \% \mathrm{w} / \mathrm{v})$ would be expected to slow transmitter diffusion by $\sim 40 \%$ (Min et al., 1998; Rusakov and Kullmann, 1998). The addition of dextran to the extracellular solution has been used previously to reduce the diffusion coefficient of glutamate in the extracellular space to alter the time course of postsynaptic receptor activation (Min et al., 1998; Nielsen et al., 2004; Piet et al., 2004; Satake et al., 2006). As expected, dextran slowed diffusion of dopamine in free solution by a factor that was dependent on the distance between the site of application and detection. The effect of dextran was minor when dopamine was applied at a distance of $3 \mu \mathrm{m}$ from the carbon fiber. When applied at a distance of $50 \mu \mathrm{m}$, the duration of the signal was dramatically affected. In the VTA, dextran decreased the peak amplitude and slowed the kinetics of the electrochemically measured extracellular dopamine transient evoked by electrical stimulation. Likewise dextran reduced the amplitude and slowed the kinetics of the electrophysiologically measured $\mathrm{D}_{2}$ receptor-mediated current produced by the iontophoresis of dopamine. This indicates in both cases that the actions of dopamine occurred over an relatively large distance. In contrast, dextran did not have an effect on the amplitude or the kinetics of the $\mathrm{D}_{2^{-}}$ IPSC. The simplest explanation of these results is that the release of dopamine that underlies the IPSC must act on $\mathrm{D}_{2}$ receptors that are located near the site of release. Therefore although dopamine can diffuse a significant distance following release, this extended diffusion does not lead to the activation of $D_{2}$ receptors that mediate the IPSC. One potential caveat from the use of dextran with FSCV is that dextran may coat the carbon fiber electrode and prevent the oxidation of dopamine. Thus by inhibiting the reaction on the carbon fiber dextran could give the false interpretation of slowing the free diffusion of dopamine. This appears to not be the case as dextran had a relatively minor effect on the detection of dopamine when it was applied to the carbon fiber from a distance of only $3 \mu \mathrm{m}$ (Fig. 6). Blocking transporters with cocaine had a dramatic effect on both the FSCV-measured dopamine transient and the amplitude and kinetics of $\mathrm{D}_{2}$-IPSCs, indicating that dopamine transporters tightly regulate the presence of dopamine and the time course of transmission in the midbrain.

\section{Conclusions}

Slowing the diffusion of dopamine in the midbrain decreased the amplitude and slowed the kinetics of the dopamine transient measured electrochemically in the VTA, yet did not alter the kinetics of dopamine-dependent transmission. Together the results indicate that the carbon fiber electrode samples dopamine that diffuses some distance from the point of release. The $\mathrm{D}_{2}$ receptors that underlie the IPSC within the VTA are positioned, however, at a site close to the site of release such that their activation does not rely on the extensive diffusion of dopamine.

The results of this study indicate that the release of dopamine from axon terminals in the striatum and dendritic sites midbrain have an equal dependence on the extracellular calcium. Upon release, the time course of rise of extracellular dopamine measured electrochemically is similar in each area, despite differences in the peak amount of dopamine released. As a variety of neurological and psychiatric disorders occur due to a dysregulation of dopamine release, understanding the mechanisms that control the release and presence of dopamine following release is necessary to understand the basis of these disorders.

\section{References}

Bayer VE, Pickel VM (1990) Ultrastructural localization of tyrosine hydroxylase in the rat ventral tegmental area: relationship between immunolabeling density and neuronal associations. J Neurosci 10:2996-3013.

Beckstead MJ, Grandy DK, Wickman K, Williams JT (2004) Vesicular dopamine release elicits an inhibitory postsynaptic current in midbrain dopamine neurons. Neuron 42:939-946.

Benoit-Marand M, Borrelli E, Gonon F (2001) Inhibition of dopamine release via presynaptic $\mathrm{D}_{2}$ receptors: time course and functional characteristics in vivo. J Neurosci 21:9134-9141.

Björklund A, Lindvall O (1975) Dopamine in dendrites of substantia nigra neurons: suggestions for a role in dendritic terminals. Brain Res 83:531-537.

Chen BT, Rice ME (2001) Novel $\mathrm{Ca}^{2+}$ dependence and time course of somatodendritic dopamine release: substantia nigra versus striatum. J Neurosci 21:7841-7847.

Chen BT, Rice ME (2002) Synaptic regulation of somatodendritic dopamine release by glutamate and GABA differs between substantia nigra and ventral tegmental area. J Neurochem 81:158-169.

Chen BT, Moran KA, Avshalumov MV, Rice ME (2006) Limited regulation of somatodendritic dopamine release by voltage-sensitive Ca channels contrasted with strong regulation of axonal dopamine release. J Neurochem 96:645-655.

Cheramy A, Leviel V, Glowinski J (1981) Dendritic release of dopamine in the substantia nigra. Nature 289:537-542.

Cragg SJ, Greenfield SA (1997) Differential autoreceptor control of somatodendritic and axon terminal dopamine release in substantia nigra, ventral tegmental area, and striatum. J Neurosci 17:5738-5746.

Cragg SJ, Rice ME (2004) DAncing past the DAT at a DA synapse. Trends Neurosci 27:270-277.

Cragg SJ, Rice ME, Greenfield SA (1997a) Heterogeneity of electrically evoked dopamine release and reuptake in substantia nigra, ventral tegmental area, and striatum. J Neurophysiol 77:863-873.

Cragg SJ, Hawkey CR, Greenfield SA (1997b) Comparison of serotonin and dopamine release in substantia nigra and ventral tegmental area: region and species differences. J Neurochem 69:2378-2386.

Cragg SJ, Nicholson C, Kume-Kick J, Tao L, Rice ME (2001) Dopaminemediated volume transmission in midbrain is regulated by distinct extracellular geometry and uptake. J Neurophysiol 85:1761-1771.

Fiorillo CD, Williams JT (1998) Glutamate mediates an inhibitory postsynaptic potential in dopamine neurons. Nature 394:78-82.

Ford CP, Mark GP, Williams JT (2006) Properties and opioid inhibition of mesolimbic dopamine neurons vary according to target location. J Neurosci 26:2788-2797.

Ford CP, Beckstead MJ, Williams JT (2007) Kappa opioid inhibition of somatodendritic dopamine inhibitory postsynaptic currents. J Neurophysiol 97:883-891.

Ford CP, Phillips PE, Williams JT (2009) The time course of dopamine transmission in the ventral tegmental area. J Neurosci 29:13344-13352.

Fortin GD, Desrosiers CC, Yamaguchi N, Trudeau LE (2006) Basal somatodendritic dopamine release requires snare proteins. J Neurochem 96:1740-1749.

Garris PA, Wightman RM (1994) Different kinetics govern dopaminergic transmission in the amygdala, prefrontal cortex, and striatum: an in vivo voltammetric study. J Neurosci 14:442-450.

Geffen LB, Jessell TM, Cuello AC, Iversen LL (1976) Release of dopamine from dendrites in rat substantia nigra. Nature 260:258-260. 
German DC, Manaye KF (1993) Midbrain dopaminergic neurons (nuclei A8, A9, and A10): three-dimensional reconstruction in the rat. J Comp Neurol 331:297-309.

Heien ML, Phillips PE, Stuber GD, Seipel AT, Wightman RM (2003) Overoxidation of carbon-fiber microelectrodes enhances dopamine adsorption and increases sensitivity. Analyst 128:1413-1419.

Herdon H, Nahorski SR (1989) Investigations of the roles of dihydropyridine and omega-conotoxin-sensitive calcium channels in mediating depolarisation-evoked endogenous dopamine release from striatal slices. Naunyn Schmiedebergs Arch Pharmacol 340:36-40.

Hoffman AF, Gerhardt GA (1999) Differences in pharmacological properties of dopamine release between the substantia nigra and striatum: an in vivo electrochemical study. J Pharmacol Exp Ther 289:455-463.

Iversen L (2006) Neurotransmitter transporters and their impact on the development of psychopharmacology. Br J Pharmacol 147 [Suppl 1]:S82-S88.

Jaffe EH, Marty A, Schulte A, Chow RH (1998) Extrasynaptic vesicular transmitter release from the somata of substantia nigra neurons in rat midbrain slices. J Neurosci 18:3548-3553.

John CE, Budygin EA, Mateo Y, Jones SR (2006) Neurochemical characterization of the release and uptake of dopamine in ventral tegmental area and serotonin in substantia nigra of the mouse. J Neurochem 96:267-282.

Juraska JM, Wilson CJ, Groves PM (1977) The substantia nigra of the rat: a Golgi study. J Comp Neurol 172:585-600.

Kawagoe KT, Zimmerman JB, Wightman RM (1993) Principles of voltammetry and microelectrode surface states. J Neurosci Methods 48:225-240.

Kim Y, Park MK, Chung S (2008) Voltage-operated Ca2 + channels regulate dopamine release from somata of dopamine neurons in the substantia nigra pars compacta. Biochem Biophys Res Commun 373:665-669.

Lacey MG, Mercuri NB, North RA (1987) Dopamine acts on D2 receptors to increase potassium conductance in neurones of the rat substantia nigra zona compacta. J Physiol 392:397-416.

Li H, Waites CL, Staal RG, Dobryy Y, Park J, Sulzer DL, Edwards RH (2005) Sorting of vesicular monoamine transporter 2 to the regulated secretory pathway confers the somatodendritic exocytosis of monoamines. Neuron 48:619-633.

Madras BK, Miller GM, Fischman AJ (2005) The dopamine transporter and attention-deficit/hyperactivity disorder. Biol Psychiatry 57:1397-1409.

Meisenzahl EM, Schmitt GJ, Scheuerecker J, Möller HJ (2007) The role of dopamine for the pathophysiology of schizophrenia. Int Rev Psychiatry 19:337-345.

Michael DJ, Wightman RM (1999) Electrochemical monitoring of biogenic amine neurotransmission in real time. J Pharm Biomed Anal 19:33-46.

Min MY, Rusakov DA, Kullmann DM (1998) Activation of AMPA, kainate, and metabotropic receptors at hippocampal mossy fiber synapses: role of glutamate diffusion. Neuron 21:561-570.

Moghaddam B, Bunney BS (1989) Ionic composition of microdialysis perfusing solution alters the pharmacological responsiveness and basal outflow of striatal dopamine. J Neurochem 53:652-654.

Morikawa H, Imani F, Khodakhah K, Williams JT (2000) Inositol 1,4,5triphosphate-evoked responses in midbrain dopamine neurons. J Neurosci 20:RC103.

Nielsen TA, DiGregorio DA, Silver RA (2004) Modulation of glutamate mobility reveals the mechanism underlying slow-rising AMPAR EPSCs and the diffusion coefficient in the synaptic cleft. Neuron 42:757-771.

Nirenberg MJ, Chan J, Liu Y, Edwards RH, Pickel VM (1996) Ultrastructural localization of the vesicular monoamine transporter-2 in midbrain dopaminergic neurons: potential sites for somatodendritic storage and release of dopamine. J Neurosci 16:4135-4145.

Patel JC, Witkovsky P, Avshalumov MV, Rice ME (2009) Mobilization of calcium from intracellular stores facilitates somatodendritic dopamine release. J Neurosci 29:6568-6579.

Phillips PE, Stamford JA (2000) Differential recruitment of N-, P- and Q-type voltage-operated calcium channels in striatal dopamine release evoked by 'regular' and 'burst' firing. Brain Res 884:139-146.

Phillips PE, Hancock PJ, Stamford JA (2002) Time window of autoreceptormediated inhibition of limbic and striatal dopamine release. Synapse 44:15-22.

Piet R, Vargová L, Syková E, Poulain DA, Oliet SH (2004) Physiological contribution of the astrocytic environment of neurons to intersynaptic crosstalk. Proc Natl Acad Sci U S A 101:2151-2155.

Pucak ML, Grace AA (1994) Evidence that systemically administered dopamine antagonists activate dopamine neuron firing primarily by blockade of somatodendritic autoreceptors. J Pharmacol Exp Ther 271:1181-1192.

Rice ME, Cragg SJ (2008) Dopamine spillover after quantal release: rethinking dopamine transmission in the nigrostriatal pathway. Brain Res Rev 58:303-313.

Rice ME, Nicholson C (1991) Diffusion characteristics and extracellular volume fraction during normoxia and hypoxia in slices of rat neostriatum. J Neurophysiol 65:264-272.

Rice ME, Richards CD, Nedergaard S, Hounsgaard J, Nicholson C, Greenfield SA (1994) Direct monitoring of dopamine and 5-HT release in substantia nigra and ventral tegmental area in vitro. Exp Brain Res 100:395-406.

Rice ME, Cragg SJ, Greenfield SA (1997) Characteristics of electrically evoked somatodendritic dopamine release in substantia nigra and ventral tegmental area in vitro. J Neurophysiol 77:853-862.

Rusakov DA, Kullmann DM (1998) Geometric and viscous components of the tortuosity of the extracellular space in the brain. Proc Natl Acad Sci U S A 95:8975-8980.

Satake S, Song SY, Cao Q, Satoh H, Rusakov DA, Yanagawa Y, Ling EA, Imoto K, Konishi S (2006) Characterization of AMPA receptors targeted by the climbing fiber transmitter mediating presynaptic inhibition of GABAergic transmission at cerebellar interneuron-Purkinje cell synapses. J Neurosci 26:2278-2289.

Schmitz Y, Lee CJ, Schmauss C, Gonon F, Sulzer D (2001) Amphetamine distorts stimulation-dependent dopamine overflow: effects on $\mathrm{D}_{2}$ autoreceptors, transporters, and synaptic vesicle stores. J Neurosci 21:5916-5924.

Schultz W (2007) Behavioral dopamine signals. Trends Neurosci 30:203210.

Stamford JA (1990) Fast cyclic voltammetry: measuring transmitter release in 'real time.' J Neurosci Methods 34:67-72.

Zhou FM, Liang Y, Salas R, Zhang L, De Biasi M, Dani JA (2005) Corelease of dopamine and serotonin from striatal dopamine terminals. Neuron 46:65-74. 